\title{
PHYSICAL PROPERTIES AND WEAR COMFORT OF BIO-FIBER-EMBEDDED YARNS AND THEIR KNITTED FABRICS ACCORDING TO YARN STRUCTURES
}

\author{
Hyun Ah Kim¹, Seung Jin Kim² \\ ${ }^{1}$ Korea Research Institute for Fashion Industry, Daegu 701-170, Korea \\ ${ }^{2}$ Dept. of Fiber System Engineering, Yeungnam Univ, Gyeongsan 712-749, Korea
}

\begin{abstract}
:
This study examined the physical properties of polytrimethylene terephthalate (PTT)/Tencel/cotton air vortex yarns and the wear comfort of their knitted fabrics for high emotional garments. In fine yarn count, the initial modulus of the air vortex yarn was similar to the ring yarn because of the elastic property of the PTT fibers in the yarns. In particular, the thermal shrinkage of the air vortex yarns was higher than that of the ring yarns because of the sensible thermal shrinkage of the PTT fibers, which resulted in higher relaxation shrinkage of the air vortex knitted fabric than those of ring and compact knitted fabrics. On the basis of the wear comfort, the air vortex yarns are compatible with winter textile goods. The pilling of the air vortex knitted fabric was superior to that of the ring and compact yarns. The tactile hand of the air vortex yarn knitted fabrics was stiffer than that of the ring and compact yarn knitted fabrics. However, the harsh tactile hand of the air vortex knitted fabric was estimated to improve in the thinner fabrics by the low elastic modulus of fine yarn because of the PTT fibers in the air vortex yarns.
\end{abstract}

\section{Keywords:}

eco-friendly fiber, thermal conductivity, tactile hand, pilling

\section{Introduction}

The great progress in the spinning process focused on improving both the yarn quality and productivity, which has brought about the development of air-jet, air vortex, and compact spinning. On the other hand, polytrimethylene terephthalate (PTT), an eco-friendly fiber based on corn, was developed to improve the low elastic recovery, which was a shortcoming of the polyester fibers. Considerable researches related to air vortex yarns have been carried out using cotton, rayon, and Tencel fibers. These studies [1, 2, 5, 17, 21, 23] examined the relationship between the physical properties of the yarn and the process parameters of the air vortex spinning system. Ünal [23] compared the mechanical properties of fabrics made from three types of yarns spun on air vortex, ring, and rotor spinning machines using $100 \%$ cotton fibers. Zhao et al. [24] examined the physical properties of the yarns and their knitted fabrics made of PTT, wool, Tencel, and quick dry PET on a ring spinning system. Suzuki et al. [22] examined the hand and mechanical properties of air vortex yarns and their knitted fabrics using rayon staple fibers. In an early study, Das et al. [3, 9] investigated the physical properties of the cotton/ acrylic air vortex yarns and their fabrics compared to the ring and compact yarns. Kilic et al. [9, 10] compared the physical properties of cotton/Tencel air vortex yarns with the ring and compact yarns. On the other hand, according to other studies $[2,5]$ the pilling characteristics of air vortex knitted fabrics made of cotton/rayon were superior to that of the ring and other spinning systems because of less yarn hairiness of the air vortex yarn. Li et al. [12] examined the dimensional stability and mechanical properties of PET/wool air vortex fabrics. Despite this, there is no consensus among their findings, that is, the differences in the yarn physical properties of the air vortex yarn compared to the ring and other yarns were noted according to the staple fiber materials, such as cotton, rayon, and wool, used in each study. In addition, the fabric hand and wearing performance of the fabrics made of air vortex and ring yarns showed slightly different findings according to the fiber materials. Recently, PTT has been used for high emotional garment fabrics because of its high elastic property and ecofriendly characteristics; therefore, PTT has been the focus of the textile materials for high functional and eco-friendly fabrics. Liu et al. [13], Luo et al. [14, 15], and Ovejero et al. [18] examined PTT filaments and their fabrics. Recently, Kim [11] investigated the physical properties of PTT- and wool-imbedded air vortex yarns and the wear comfort of their knitted fabrics for high emotional garments. On the other hand, the physical properties of fabrics made of air vortex yarns using PTT, including ecofriendly staple fibers, has attracted less attention. Therefore, this study examined the physical properties of the air vortex yarns compared to the ring and compact yarns using the PTT/ Tencel/cotton fibers. In addition, this study examined the tactile hand and wear comfort of knitted fabrics made of the air vortex yarns and the applicable possibility of the PTT fibers to the air vortex yarn fabrics for emotional garments.

\section{Experimental}

\subsection{Yarn preparation}

Different staple yarns were made using PTT/cotton/Tencelblended fibers on the vortex, compact, and ring spinning frames. Table 1 lists the fiber characteristics and processing 
conditions of the vortex, compact, and ring spinning processes. The fiber characteristics of cotton such as fineness, length, and tenacity were measured using HVI system, and their average and coefficient of variance (CV, \%) values were calculated using experimental data measured by the fiber specimens prepared from 10 bales. The mixed percentage of the blended fibers was $30 \%$ of PTT, $50 \%$ of Tencel, and $20 \%$ of cotton. The fineness of the PTT staple fiber was $1.2 \mathrm{~d}$; the average fiber length was $38 \mathrm{~mm}$ for the air vortex spinning frame and $40 \mathrm{~mm}$ for the ring and compact systems. The fineness of the Tencel was 1.17 $\mathrm{d}$; the mean fiber length was $38 \mathrm{~mm}$. The average fineness of the cotton fiber was $1.4 \mathrm{~d}$; the mean fiber length was $28 \mathrm{~mm}$. The spinning frames used in this study were air vortex (Murata, MVS 861), compact (Toyota, RX 300), and ring (Zinser MAT 670). The spindle speed of the ring and compact spinning frame was $10,000 \mathrm{rpm}$, the twist multiplier was 3.8 , and the air pressure of the compact roller on the compact spinning frame was $3.8 \mathrm{kPa}$. The spinning speed of the air vortex spinning was
$370 \mathrm{~m} / \mathrm{min}$, the air pressure of the nozzle was 0.6 bar, and the distance of the nozzle was $20 \mathrm{~mm}$. The yarn linear density of 20,30 , and $40 \mathrm{Ne}$ was spun on the three types of spinning frames, respectively.

\subsection{Knitted fabric preparation}

Two-folded (2/20 Ne, 2/30 Ne) and three-folded yarns (3/40 $\mathrm{Ne}$ ) were made on a winder (SamChang Co., Korea) with spandex 20 denier using 20,30, and 40 Ne single yarns, which were spun on each spinning frame. Nine types of the knitted fabric specimens were made using these three types of yarns with a plain knit pattern, 14 gauge on the weft knitting machine (NSSG 14-122 SV, Shima, Japan). Different densities of the course and wale directions were applied according to the yarn linear density, and Table 2 shows the stitch density of the each knitted fabric specimen according to the yarn linear density. Table 2 lists the knitted fabric specimens.

Table 1. Details of the fiber characteristics and spinning process conditions

\begin{tabular}{|c|c|c|c|c|c|c|c|c|c|}
\hline \multirow{3}{*}{$\begin{array}{c}\text { Spinning } \\
\mathrm{m} / \mathrm{c}\end{array}$} & \multicolumn{8}{|c|}{ Fiber characteristics } & \multirow{3}{*}{$\begin{array}{c}\text { Linear } \\
\text { density } \\
(\mathrm{Ne})\end{array}$} \\
\hline & \multirow{2}{*}{$\begin{array}{c}\text { Blended } \\
\text { fibers }\end{array}$} & \multirow{2}{*}{$\begin{array}{c}\text { Blend } \\
\text { ratio (\%) }\end{array}$} & \multicolumn{2}{|c|}{ Fineness(d) } & \multicolumn{2}{|c|}{ Length (mm) } & \multicolumn{2}{|c|}{ Tenacity (cN/tex) } & \\
\hline & & & Mean & CV (\%) & Mean & CV (\%) & Mean & CV (\%) & \\
\hline \multirow{3}{*}{ Air vortex } & PTT & 30 & 1.20 & - & 38 & - & 53.4 & 4.1 & \multirow{3}{*}{$20,30,40$} \\
\hline & Tencel & 50 & 1.17 & - & 38 & - & 38.2 & 4.6 & \\
\hline & Cotton & 20 & 1.40 & 4.87 & 28 & 1.71 & 30.5 & 2.68 & \\
\hline \multirow{3}{*}{ Compact } & PTT & 30 & 1.20 & - & 40 & - & 53.4 & 4.1 & \multirow{3}{*}{$20,30,40$} \\
\hline & Tencel & 50 & 1.17 & - & 38 & - & 38.2 & 4.6 & \\
\hline & Cotton & 20 & 1.40 & 4.87 & 28 & 1.71 & 30.5 & 2.68 & \\
\hline \multirow{3}{*}{ Ring } & PTT & 30 & 1.20 & - & 40 & - & 53.4 & 4.1 & \multirow{3}{*}{$20,30,40$} \\
\hline & Tencel & 50 & 1.17 & - & 38 & - & 38.2 & 4.6 & \\
\hline & Cotton & 20 & 1.40 & 4.87 & 28 & 1.71 & 30.5 & 2.68 & \\
\hline
\end{tabular}

Table 2. Specifications of the knitted fabric specimens

\begin{tabular}{|c|c|c|c|c|c|}
\hline \multirow[t]{2}{*}{ Specimen no. } & \multirow[t]{2}{*}{ Spinning method } & \multirow{2}{*}{$\begin{array}{l}\text { Yarn linear } \\
\text { density (Ne) }\end{array}$} & $\begin{array}{c}\text { Density } \\
\text { (threads/in) }\end{array}$ & \multirow{2}{*}{$\begin{array}{l}\text { Stitch density } \\
\text { (threads/in }{ }^{2} \text { ) }\end{array}$} & \multirow[t]{2}{*}{ Structure } \\
\hline & & & Course $\times$ Wale & & \\
\hline 1 & \multirow{3}{*}{ Air vortex } & $2 / 20$ & $22 \times 29$ & 638 & \multirow{9}{*}{ Plain } \\
\hline 2 & & $2 / 30$ & $25 \times 27$ & 675 & \\
\hline 3 & & $3 / 40$ & $23 \times 26$ & 598 & \\
\hline 4 & \multirow{3}{*}{ Compact } & $2 / 20$ & $22 \times 29$ & 638 & \\
\hline 5 & & $2 / 30$ & $24 \times 33$ & 792 & \\
\hline 6 & & $3 / 40$ & $23 \times 25$ & 575 & \\
\hline 7 & \multirow{3}{*}{ Ring } & $2 / 20$ & $22 \times 30$ & 660 & \\
\hline 8 & & $2 / 30$ & $24 \times 30$ & 720 & \\
\hline 9 & & $3 / 40$ & $22 \times 26$ & 572 & \\
\hline
\end{tabular}




\subsection{Measurement of the yarn and fabric physical properties}

\subsubsection{Yarn physical property}

The unevenness of the nine types of staple yarns was measured using an Uster 5 evenness tester (Uster Ltd. Co., Switzerland). The U\%, thin, thick, and nep were measured using the Uster 5 apparatus. The yarn tensile property was measured using a Testomeric Micro 350 (UK). The tenacity, breaking strain, and tensile modulus were measured with a gauge length of $20 \mathrm{~mm}$ and the testing speed was $100 \mathrm{~mm} / \mathrm{min}$. Twenty tests were carried out for each specimen, and the average value and standard deviation (SD) were assessed. The dry thermal shrinkage was measured under the following conditions: $180^{\circ} \mathrm{C}$ dry heat for 30 min treatment in a dry heater chamber. The wet thermal shrinkage was measured at $100^{\circ} \mathrm{C}$ wet heat for a 30-min treatment in a water bath. Ten tests were carried out for each specimen, and the average value and SD were calculated. The length of the yarn specimen, as a hank shape before $\left(l_{1}\right)$ and after $\left(l_{2}\right)$ dry (wet) heat treatment, was measured under $0.1 \mathrm{~g} / \mathrm{d}$; the initial load and dry(wet) thermal shrinkage were calculated using equation (1).

$$
\frac{l_{1}-l_{2}}{l_{1}} \times 100
$$

The longitudinal image of the yarn specimen and the surface image of the knitted fabric specimens were examined by fieldemission scanning electron microscopy (FE-SEM S-4100) and optical microscopy (i Camscope-305A).

\subsection{Physical properties and wear comfort of the knitted fabrics}

The mechanical properties of the knitted fabrics were measured using a KES-FB system. The tensile, shear, bending, compression, and surface properties of the knitted fabric specimens were measured with 16 mechanical properties including the fabric weight and thickness [18]. Three tests were conducted for each specimen. The relaxation shrinkage of the knitted fabric specimen was measured using the FAST-4 system. A $20 \mathrm{~cm} \times 20 \mathrm{~cm}$ knitted fabric specimen was dried for $10 \mathrm{~min}$ in a dryer and the $L_{1}$ was then measured. The specimen was then soaked for $30 \mathrm{~min}$ at $30^{\circ} \mathrm{C}$ in a water bath and the $L_{2}$ was measured. The specimen was dried for $15 \mathrm{~min}$ at $105^{\circ} \mathrm{C}$ in a dryer and the $L_{3}$ was measured. The relaxation shrinkage (RS) was calculated using equation (2). Three tests were carried out for each specimen.

$$
R S=\frac{L_{1}-L_{3}}{L_{1}} \times 100
$$

The pilling property was measured using the pilling box method according to KSK ISO 12945-1:2009. The specimen was removed from the pilling box measuring apparatus after 1440 revolutions, and the surface image of the specimen was then taken using a video microscope and scanning electron microscope (SEM), respectively. The wicking, drying, and thermal property as a wear comfort related to the moisture and heat transmission were measured. Wicking was measured using the Bireck method (KSK 0815). About $10 \mathrm{~mm}$ of the one end of the strip of $20 \mathrm{~cm} \times 2.5 \mathrm{~cm}$ in size was submerged into the distilled water of $27 \pm 2^{\circ} \mathrm{C}$, and the wicking length (mm) was then measured after $10 \mathrm{~min}$ and taken as mean value of the coarse and wale directions. Three tests were conducted for each specimen. The drying property was also measured by KSK0815 using a drying tester (Intec. Co. Ltd., Japan). A square-shaped knitted fabric specimen, $40 \mathrm{~cm} \times 40 \mathrm{~cm}$ in size, was submerged fully in distilled water in a $27 \pm 2{ }^{\circ} \mathrm{C}$ water bath, and the absorbed specimen was then hung on the equipment. The weight of hung specimen was measured according to the time, and the time (minutes) elapsed until the specimen weight was relatively constant was recorded as the drying rate. Three tests were carried out for each specimen. The thermal property was measured using a KES-F7 (Thermolabo II, Kato Tech. Co. Ltd, Japan). The thermal conductivity $(\mathrm{K})$ and maximum heat flow $\left(Q_{\max }\right)$ were assessed using this apparatus. The thermal conductivity (K) was measured at $22 \pm 1^{\circ} \mathrm{C}$ and $70 \pm 5 \%$ of relative humidity and calculated using equation (3).

$$
K=\frac{W \cdot D}{\Delta T}
$$

where $\mathrm{K}\left(\mathrm{W} / \mathrm{m}^{\circ} \mathrm{C}\right)$ is the thermal conductivity, $\mathrm{W}$ is the heat loss $\left(W / \mathrm{cm}^{2}\right), D$ is the thickness $(\mathrm{cm})$ of the specimen, $\Delta T$ is the temperature difference $\left({ }^{\circ} \mathrm{C}\right)$, and $\mathrm{Q}_{\text {max }}$ is the maximum heat flow $\left(\mathrm{J} / \mathrm{cm}^{2} \cdot \mathrm{s}\right)$. Three tests were conducted for each specimen.

\section{Results and discussion}

\subsection{Physical properties of the air vortex yarns}

Table 3 lists the yarn physical properties according to the spinning method. As listed in Table 3, the unevenness (U\%) of the air vortex yarns was higher than those of the compact and ring yarns. The imperfections of the air vortex yarns, particularly in $40 \mathrm{Ne}$, such as thin, thick, and nep, were much more common than those of the compact and ring yarns, which was attributed to the fasciated yarn structure of the air vortex yarns, that is, to the alternative presence of thick and thin places along the longitudinal direction of the yarn because of the formation of a periodical fasciated twist by the wrapper fibers on the yarn surface. Similar findings in previous studies have been reported for $100 \%$ cotton air vortex yarns [2] and cotton/Tencel and cotton/modal air vortex blend yarns [5]. This means that PTT/Tencel/cotton blend fibers are applicable to the air vortex spinning system such as $100 \%$ cotton, cotton/ Tencel and cotton/modal blend fibers. Figure 1 presents optical microscopic images of the yarn specimens. As shown in Figure 1 , the air vortex yarns were more irregular than the compact and ring yarns, but the hairy fibers on the yarn surface of the air vortex yarns were fewer in number and shorter than those of the compact and ring yarns. This was caused by the wrapper fibers on the yarn surface, which makes a wild fiber loop to protect the hairy fibers from coming out from the inner part of the yarns. Beceren et al. [2], Erdumlu et al. [5], and Soe et al. [21] reported similar findings.

\subsection{Mechanical properties of the air vortex yarns}

As presented in Table 3, the breaking strength and breaking strain of the air vortex yarns were lower than those of the 
Table 3. Details of the yarn physical properties

\begin{tabular}{|c|c|c|c|c|c|c|c|c|c|c|c|c|c|c|c|c|c|}
\hline \multirow{3}{*}{\multicolumn{2}{|c|}{ 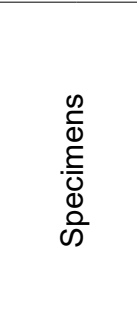 }} & \multicolumn{2}{|c|}{$\begin{array}{l}\text { Measured } \\
\text { yarn linear } \\
\text { density(Ne) }\end{array}$} & \multicolumn{4}{|c|}{ Unevenness } & \multicolumn{6}{|c|}{ Tensile property } & \multicolumn{4}{|c|}{ Thermal shrinkage } \\
\hline & & \multirow[t]{2}{*}{ Mean } & \multirow[t]{2}{*}{$\begin{array}{l}\text { CV } \\
(\%)\end{array}$} & \multirow[t]{2}{*}{ U\% } & \multirow[t]{2}{*}{ Thin } & \multirow[t]{2}{*}{ Thick } & \multirow[t]{2}{*}{ Nep } & \multicolumn{2}{|c|}{$\begin{array}{l}\text { Tenacity } \\
\text { (cN/tex) }\end{array}$} & \multicolumn{2}{|c|}{$\begin{array}{l}\text { Breaking } \\
\text { strain (\%) }\end{array}$} & \multicolumn{2}{|c|}{$\begin{array}{l}\text { Initial } \\
\text { modulus } \\
\text { (cN/dtex) }\end{array}$} & \multicolumn{2}{|c|}{$\begin{array}{c}\text { Dry shrinkage } \\
(\%)\end{array}$} & \multicolumn{2}{|c|}{$\begin{array}{c}\text { Wet } \\
\text { shrinkage } \\
(\%)\end{array}$} \\
\hline & & & & & & & & Mean & SD & Mean & SD & Mean & SD & Mean & SD & Mean & SD \\
\hline \multirow{3}{*}{ 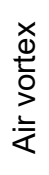 } & 20 & 20.24 & 1.1 & 8.63 & 0 & 3.2 & 5.7 & 13.8 & 0.96 & 6.63 & 1.23 & 105.8 & 16.7 & 3.1 & 0.12 & 5.0 & 0.11 \\
\hline & 30 & 29.70 & 1.3 & 10.6 & 6.3 & 16.7 & 27.2 & 13.6 & 0.91 & 6.43 & 1.15 & 104.0 & 14.7 & 2.1 & 0.14 & 3.0 & 0.12 \\
\hline & 40 & 40.43 & 1.5 & 12.67 & 119.3 & 102 & 75.3 & 13.0 & 0.89 & 5.65 & 1.07 & 136.5 & 23.1 & 2.4 & 0.15 & 2.5 & 0.12 \\
\hline \multirow{3}{*}{ 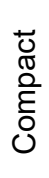 } & 20 & 20.32 & 0.8 & 7.68 & 0 & 2.5 & 5 & 16.9 & 0.82 & 8.86 & 1.51 & 95.0 & 11.7 & 5.9 & 0.11 & 4.6 & 0.12 \\
\hline & 30 & 30.18 & 0.9 & 8.90 & 0 & 6.7 & 23.3 & 15.9 & 0.80 & 7.41 & 1.49 & 111.5 & 19.4 & 3.3 & 0.13 & 3.8 & 0.11 \\
\hline & 40 & 39.89 & 1.1 & 10.11 & 2.8 & 25 & 57 & 15.6 & 0.78 & 6.62 & 1.31 & 115.1 & 19.2 & 3.2 & 0.14 & 3.0 & 0.11 \\
\hline \multirow{3}{*}{ 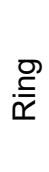 } & 20 & 19.43 & 0.9 & 7.82 & 0 & 2.3 & 8 & 17.5 & 0.81 & 10.01 & 1.61 & 85.5 & 16.7 & 1.0 & 0.11 & 1.6 & 0.11 \\
\hline & 30 & 29.82 & 1.0 & 9.29 & 0 & 11 & 26.7 & 16.1 & 0.79 & 8.31 & 1.54 & 101.8 & 15.0 & 1.4 & 0.13 & 1.5 & 0.12 \\
\hline & 40 & 40.98 & 1.2 & 10.63 & 5.3 & 38.3 & 71.3 & 15.4 & 0.77 & 6.64 & 1.29 & 98.3 & 17.5 & 0.7 & 0.15 & 1.0 & 0.13 \\
\hline
\end{tabular}

Abbreviation: SD, standard deviation.

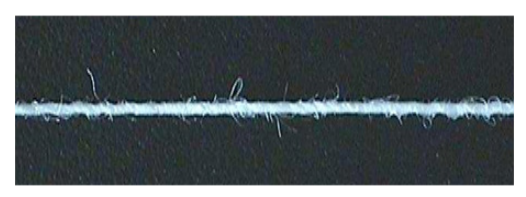

$20 \mathrm{Ne}$

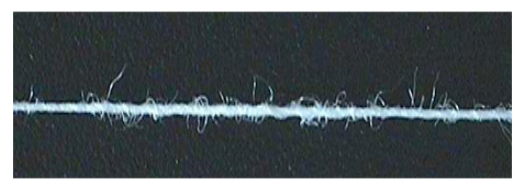

$30 \mathrm{Ne}$

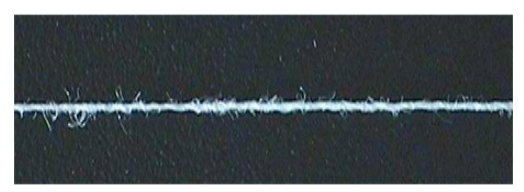

$40 \mathrm{Ne}$

(a)

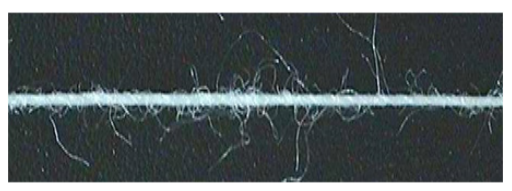

$20 \mathrm{Ne}$

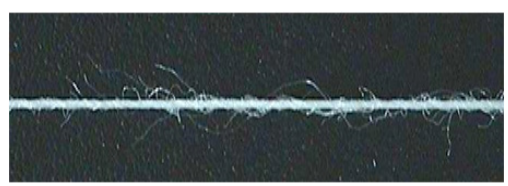

$30 \mathrm{Ne}$

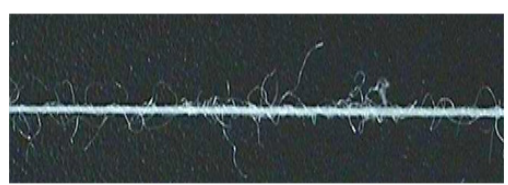

$40 \mathrm{Ne}$

(b)

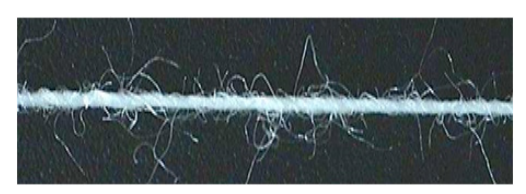

$20 \mathrm{Ne}$

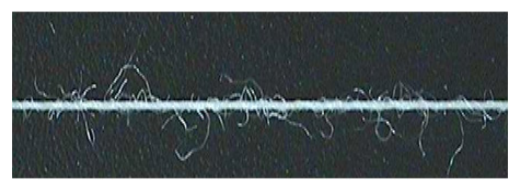

$30 \mathrm{Ne}$

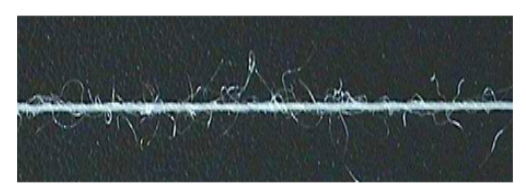

$40 \mathrm{Ne}$

(c)

Figure 1. Microscopic images of the yarn specimens: (a) vortex, (b) compact, and (c) ring.

compact and ring yarns. This was attributed to the loose wrapper fibers formed on the yarn surface by the whirled air in the vortex nozzle and to the loop formed by wild fibers on the yarn surface, which makes the fibers in the yarns less resistant to external loads. These results were similar to those of previous studies (Beceren et al. [2], Erdumlu et al [5] and Soe et al. [21]). Regarding the initial modulus of the yarn specimens, the air vortex yarns and ring yarns showed the highest and lowest initial modulus, respectively, which was caused by the parallel fibers in the core of the air vortex yarns and by the helical fibers in the ring yarns. Figure 2 presents the load elongation diagram of the air vortex, compact, and ring yarns.

As shown in Figure 2, the breaking strength and strain of the air vortex yarns were lower than those of the compact and ring yarns, respectively. On the other hand, in Figure 2(c), the initial modulus of the air vortex yarn was observed as similar value to the ring yarn, which was attributed to the contribution of the elastic property of PTT fibers in the yarns, that is, it shows that the elastic property of the PTT fibers in the fine yarn count $(40 \mathrm{Ne})$ can contribute at low elastic modulus of the air vortex yarn. Figure 3 presents SEM images of the yarn specimens 
according to the spinning method.

Parallel fibers in the core of the air vortex yarns and the wrapper fibers on the air vortex yarn surface with the wild loops were observed, and fewer hairy fibers were found on the air vortex yarns compared to the compact and ring yarns, but helical fibers were noted on the surface of the ring yarn.

\subsection{Thermal shrinkage of the air vortex yarns}

PTT has a $\mathrm{Tg}$ of approximately $40^{\circ} \mathrm{C}$, so thermal shrinkage occurs because of the low $\mathrm{Tg}$ and reorientation of the molecular chain in the amorphous region because they move to a more stable state thermodynamically. The thermal shrinkage of
PTT including the staple yarns is very important and affects the fabric physical properties. As shown in Table 3, the dry shrinkage of the air vortex yarn ranged from $2 \%$ to $3 \%$, and the level of wet shrinkage was $2.5-5 \%$. These were much higher than those of the ring yarns, which was caused by the bulky yarn structure of the air vortex yarn, that is, the wet and dry thermal shrinkages by the rearrangement of the PTT fibers by thermal stress in the air vortex yarn as exposed to wet and dry heats were higher than those of the ring yarns because of low $\mathrm{Tg}$ of the PTT fibers. This means that the thermal shrinkage of the PTT-blended air vortex yarn is mostly influenced by PTT fiber in the bulky yarn structure with the periodical fascinated twist by the wrapper fibers on the air vortex yarn surface, but not influencing by PTT fibers in the PTT-blended ring yarn.

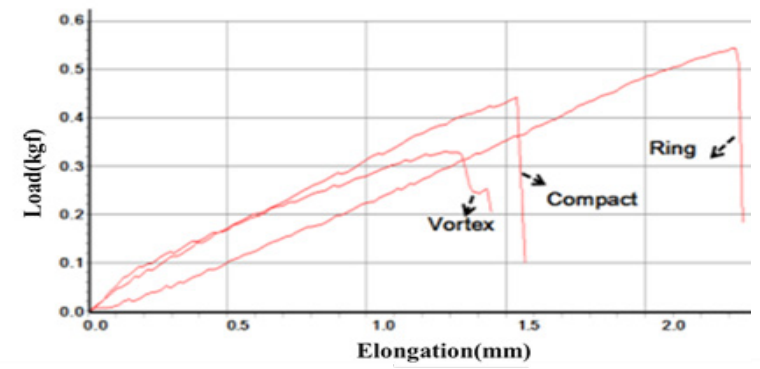

(a)

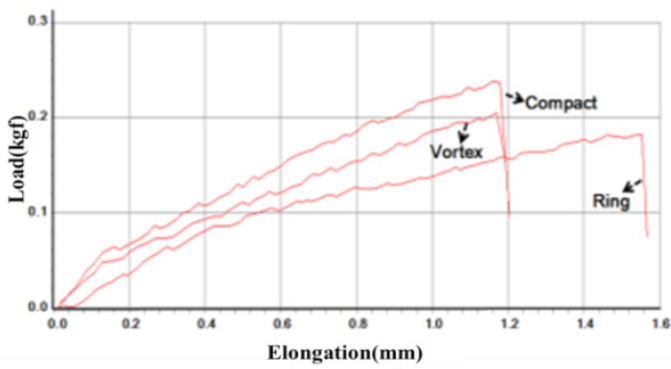

(b)

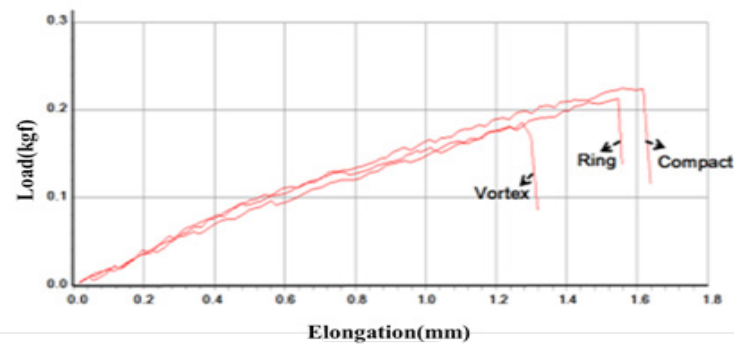

(c)

Figure 2. Load elongation diagram of the yarn specimens: (a) $20 \mathrm{Ne}$, (b) $30 \mathrm{Ne}$, and (c) $40 \mathrm{Ne}$.

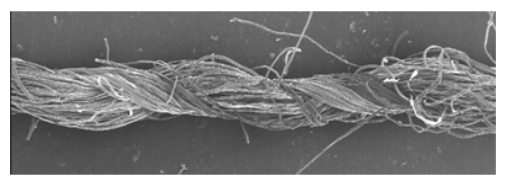

$20 \mathrm{Ne}$

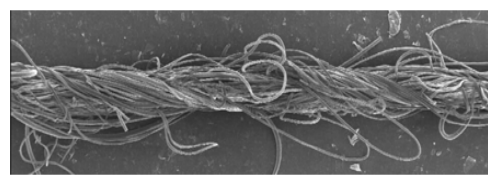

$30 \mathrm{Ne}$

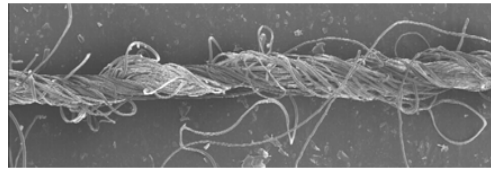

$40 \mathrm{Ne}$

(a)

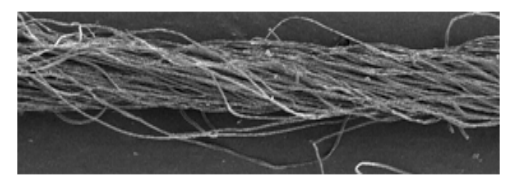

$20 \mathrm{Ne}$

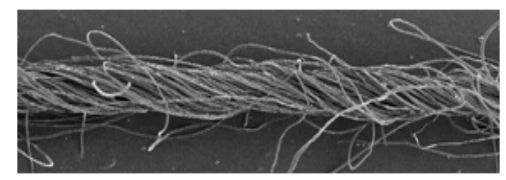

$30 \mathrm{Ne}$

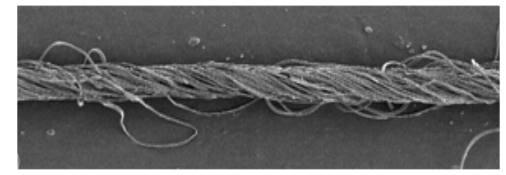

$40 \mathrm{Ne}$

(b)

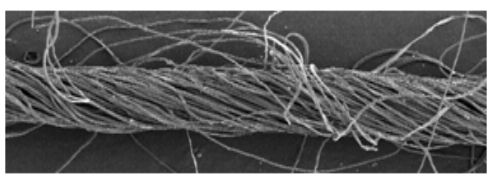

$20 \mathrm{Ne}$

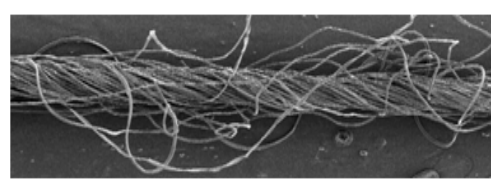

$30 \mathrm{Ne}$

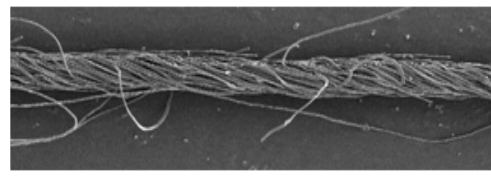

$40 \mathrm{Ne}$

(c)

Figure 3. SEM images of the yarn specimens according to the spinning method: (a) vortex, (b) compact, and (c) ring. 
These results coincided well with those reported by Erdumlu et al. [5] and Li et al. [12]

\subsection{Wear comfort property of the air vortex knitted fabrics}

Figure 4 presents the wicking rate, drying rate, thermal conductivity, and $Q_{\max }$ according to the spinning method. As shown in Figure 4 (a) and (b), the wicking rates of the air vortex knitted fabrics were lower than those of the compact and ring knitted fabrics, but the drying rates of the air vortex knitted fabrics were shorter than those of the compact and ring knitted fabrics. These results were attributed to the air vortex yarn structure, that is, the absorbed water from the end of the air vortex yarn was prevented from moving upward by the capillary effect because of the yarn structure with the parallel fibers bundle in the core and the wrapper fibers formed periodically on the yarn surface with large pores inside the air vortex yarn. These findings were similar to previous studies $[6,7,20]$. On the other hand, the shorter drying rate of the air vortex knitted fabrics compared to the ring and compact knitted fabrics was caused by larger voids in the air vortex yarns, which resulted in rapid vapor transmission by diffusion. Das et al. [3], Mhetre et al. [16], and Öztürk et al. [19] reported similar findings using

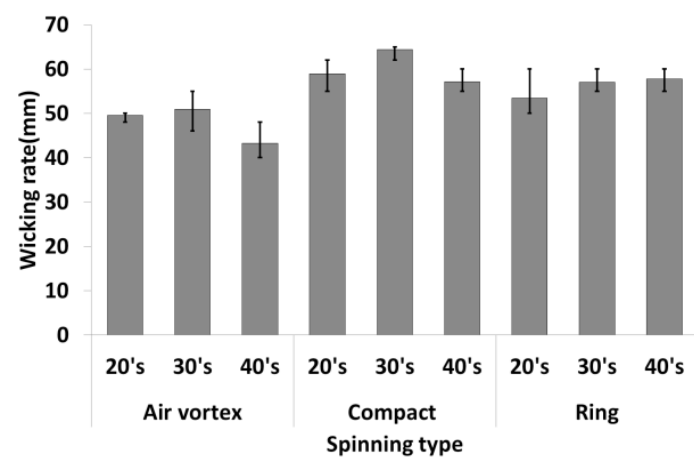

(a)

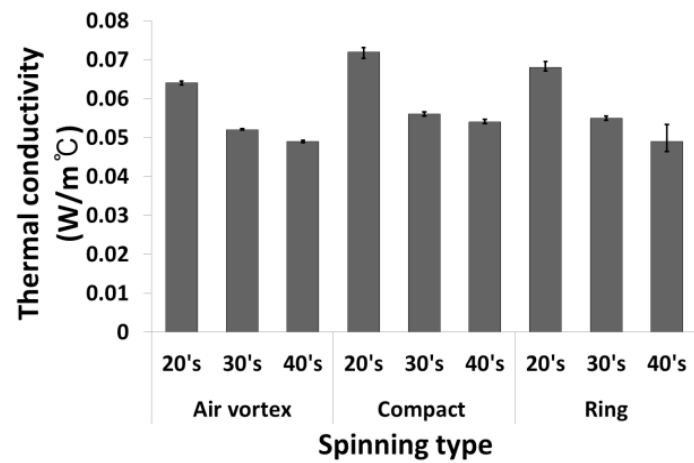

(c) cotton and acrylic staple yarns. In Figure 4(c) and (d), the thermal conductivity and $Q_{\max }$ of the air vortex knitted fabrics were lower than those of the compact and ring knitted fabrics, which were attributed to the air vortex yarn structure explained previously, that is, more air voids in the fasciated bulky air vortex yarn entrap the neighboring air, which prevents heat flow from the inner layer to the outer layer of the air vortex knitted fabric. These thermal results mean that air vortex yarns are compatible with winter textile goods, and ring and compact yarns are suitable for summer ones.

\subsection{Dimensional stability and pilling property of the air vortex knitted fabrics}

Table 4 lists the relaxation shrinkage and pilling of the knitted fabrics according to the spinning method. The relaxation shrinkage of the air vortex knitted fabrics was higher than those of the ring and compact knitted fabrics, which was attributed to the large deformation because of the rearrangement of fibers in the yarn from the residual thermal stress caused by the bulky yarn structure of the air vortex. According to Erdumlu et al. [5] and Li et al. [12], the wet thermal shrinkage of the air vortex yarn made from cotton and rayon fibers was higher than

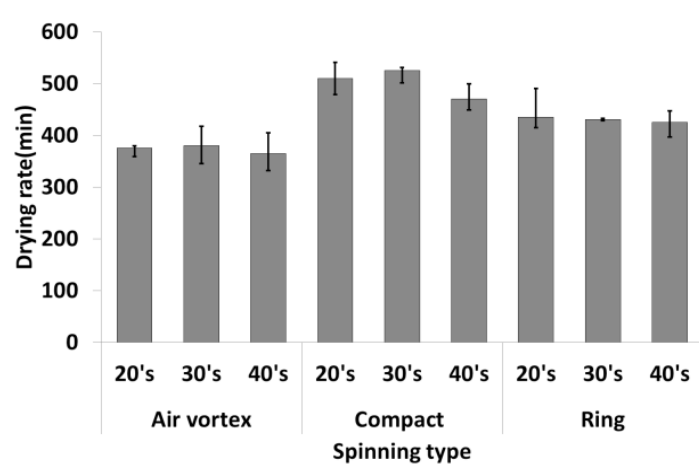

(b)

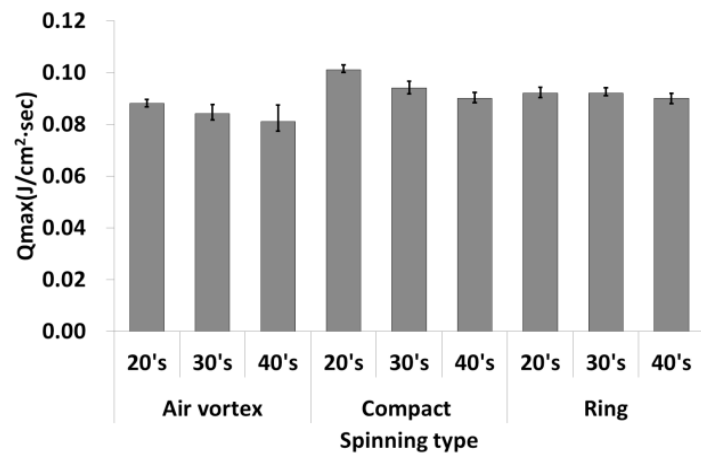

(d)

Figure 4. Water moisture and heat transmission of the knitted fabrics: (a) wicking rate, (b) drying rate, (c) thermal conductivity, and (d) $Q_{\text {max }}$

Table 4. Dimensional stability and pilling of the knitted fabrics according to the spinning method

\begin{tabular}{|c|c|c|c|c|c|c|c|c|c|}
\hline \multirow{3}{*}{ Specimens no. } & \multicolumn{3}{|c|}{ Air vortex } & \multicolumn{3}{|c|}{ Compact } & \multicolumn{3}{|c|}{ Ring } \\
\hline & 1 & 2 & 3 & 4 & 5 & 6 & 7 & 8 & 9 \\
\hline & $20 \mathrm{Ne}$ & $30 \mathrm{Ne}$ & $40 \mathrm{Ne}$ & $20 \mathrm{Ne}$ & $30 \mathrm{Ne}$ & $40 \mathrm{Ne}$ & $20 \mathrm{Ne}$ & $30 \mathrm{Ne}$ & $40 \mathrm{Ne}$ \\
\hline $\begin{array}{c}\text { Relaxation } \\
\text { shrinkage (\%) }\end{array}$ & 3.61 & 6.70 & 6.14 & 1.30 & 4.35 & 4.49 & 4.53 & 5.68 & 5.53 \\
\hline Pilling (grade) & 4 & 4 & 4 & $1-2$ & 2 & 2 & $2-3$ & 3 & $3-4$ \\
\hline
\end{tabular}


that of the ring yarn, which was similar to the present findings. Figure 5 presents optical microscopic images of the pilling of the knitted fabric specimens according to the spinning method. Considerably less pilling was observed in the air vortex knitted fabric than that in the compact and ring knitted fabrics, which was attributed to the fewer and shorter hairy fibers on the air vortex yarn surface than the ring and compact yarns.

\subsection{Tactile hand property from the mechanical properties}

Table 5 lists the fabric mechanical properties of the knitted fabric specimens $(20 \mathrm{Ne})$ according to the spinning method measured by the KES-FB system [8]. Figure 6 presents a diagram of the mechanical properties of the knitted fabric specimens according to the spinning method using the data listed in Table 5. As shown in Figure 6, the extensibility (EM) and tensile resilience (RT) of the air vortex knitted fabric were lower than those of the ring and compact knitted fabrics. The compressional resilience (RC) and compressional work (WC) of the air vortex knitted fabric were also lower than those of the ring and compact ones, respectively. In contrast, the bending rigidity $(\mathrm{B})$ and hysteresis $(2 \mathrm{HB})$ and the shear modulus $(\mathrm{G})$ and hysteresis $(2 \mathrm{HG})$ of the air vortex knitted fabric were higher than those of the ring and compact knitted fabrics, respectively. This means that the air vortex knitted fabric has a harsh tactile hand and poor tactile

comfort because of the low extensibility and compressibility as well as the high bending and shear rigidities. These mechanical properties of the air vortex yarn knitted fabric were attributed

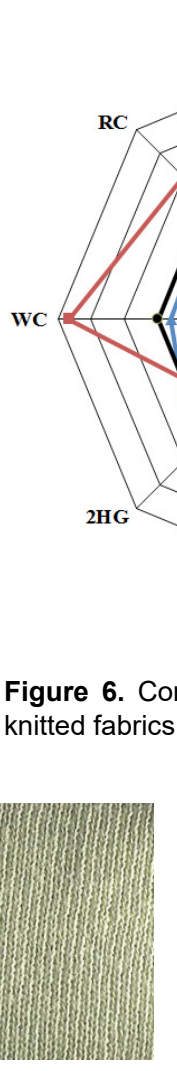

2

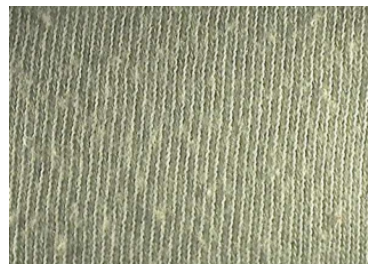

5

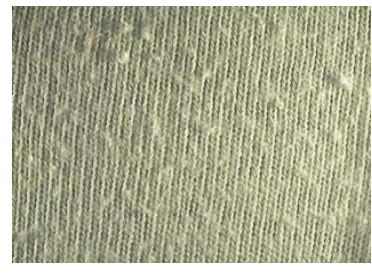

8

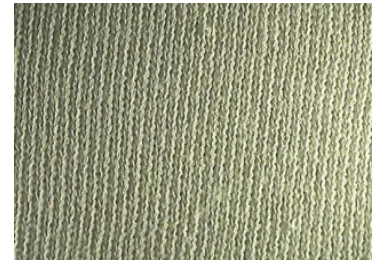

3

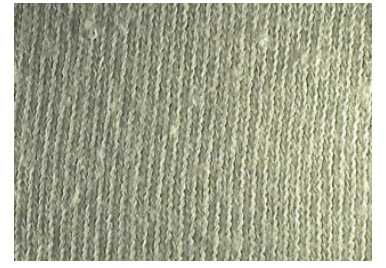

6

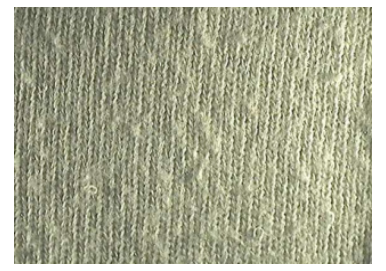

9

Figure 5. Optical microscopic images of the pilling of the knitted fabric specimens.

Table 5. Mechanical properties of the knitted fabrics according to the spinning method (20 $\mathrm{Ne})$

\begin{tabular}{|c|c|c|c|c|c|c|c|c|c|c|c|}
\hline Specimens & EM & RT & B & 2HB & G & 2HG & WC & RC & MIU & T & W \\
\hline Air vortex yarn & 22.620 & 34.190 & 0.06 & 0.08 & 0.660 & 0.950 & 0.06 & 43.130 & 0.174 & 0.962 & 18.460 \\
\hline Compact yarn & 26.890 & 37.620 & 0.04 & 0.06 & 0.410 & 0.630 & 0.10 & 54.430 & 0.191 & 1.131 & 20.620 \\
\hline Ring yarn & 30.140 & 34.140 & 0.06 & 0.08 & 0.490 & 0.850 & 0.064 & 45.280 & 0.175 & 1.04 & 19.280 \\
\hline
\end{tabular}

Abbreviations: MIU, mean friction coefficient; T, thickness; W, weight. 
to the fasciated air vortex yarn structure with the parallel fibers bundles in the core and wrapper fibers formed periodically on the yarn surface, which resulted in low extensibility and tensile resilience in the longitudinal direction of the fabric, as well as in high bending and shear properties and low compressional resilience and compressional work in the lateral direction of the fabric.

\section{Conclusion}

The wear comfort of the bio-fiber PTT/Tencel/cotton air vortex yarns and their knitted fabrics for emotional garments were studied with tactile hand property to assess the applications of the PTT staple fibers to air vortex yarns compared to ring and compact yarns. The unevenness of the air vortex yarns was higher than that of the ring and compact yarns, which resulted in low tenacity and breaking strain of the air vortex yarns. The hairiness of the air vortex yarns, however, was lower and shorter than that of the ring and compact yarns. The initial modulus of the air vortex yarns was higher than those of the ring and compact yarns. However, in fine yarn count $(40 \mathrm{Ne})$, the initial modulus of the air vortex yarn was similar to that of the ring yarn, which means that the elastic property of the PTT fibers in the air vortex yarn affects the elasticity of yarn irrespective of spinning method, that is, yarn structure. The thermal shrinkage of the air vortex yarns was higher than that of the ring yarns, which was caused by the sensible thermal shrinkage of the PTT fibers on the bulky yarn surface and the core part of the air vortex yarns. The wicking property of the knitted fabric by the air vortex yarns was poorer than those by the ring and compact yarns. On the other hand, the drying property of the knitted fabric by the air vortex yarns was superior to that of the ring and compact yarns, which was explained by the greater water vapor transport because of the larger openness between the fibers in the air vortex yarns. The thermal conductivity of the knitted fabric by the air vortex yarn was lower than that of the ring and compact yarns, and the maximum heat flow $\left(Q_{\text {max }}\right)$ at the transient state of the air vortex knitted fabric was also lower than that of the ring and compact yarns. On the basis of the wear comfort, including thermal property, the air vortex yarns are compatible with winter textile goods. The relaxation shrinkage of the air vortex knitted fabric was higher than that of the knitted fabrics by the ring and compact yarns, which was attributed to the low Tg of the PTT fibers in the air vortex yarns. The pilling of the air vortex knitted fabric was superior to that of the ring and compact yarns; this was attributed to the less and short hairy fibers protruding from the air vortex yarn surface. The tactile hand of the air vortex yarn knitted fabrics was stiffer than that of the ring and compact yarns knitted fabrics, which revealed the harsh tactile wear performance of the air vortex knitted fabric. However, the harsh tactile hand of the air vortex knitted fabric was estimated to improve in the thinner fabrics by the low elastic modulus of fine yarn because of the PTT fibers in the air vortex yarns.

\section{References}

[1] Basal, G., \& Oxenham, W. (2006). Comparison of properties and structures of compact and conventional spun yarns. Textile Research Journal, 76(7), 567-575.

[2] Beceren, Y., \& Nergis, B. U. (2008). Comparison of the effects of cotton yarns produced by new, modified and conventional spinning systems on yarn and knitted fabric performance. Textile Research Journal, 78(4), 297-303.

[3] Das, A., Zimniewska, M., \& Mal, R. D. (2009). Studies on cotton-acrylic bulked yarns produced from different spinning technologies. Part II: fabric characteristics. The Journal of The Textile Institute, 100(5), 420-429.

[4] Das, A., \& Mal, R. D. (2009). Studies on cottonacrylic bulked yarns produced from different spinning technologies. Part I: yarn characteristics. The Journal of The Textile Institute, 100(1), 44-50.

[5] Erdumlu, N., Ozipek, B., Oztuna, A. S., \& Cetinkaya, S. (2009). Investigation of vortex spun yarn properties in comparison with conventional ring and open-end rotor spun yarns. Textile Research Journal, 79(7), 585-595.

[6] Hsieh, Y. L. (1995). Liquid transport in fabric structures. Textile Research Journal, 65(5), 299-307.

[7] Ito, H., \& Muraoka, Y. (1993). Water transport along textile fibers as measured by an electrical capacitance technique. Textile Research Journal, 63(7), 414-420.

[8] Kawabata, S. (1980). The standardization and analysis of hand evaluation. The hand evaluation and standardization committee.

[9] Kilic, G. B., \& Sülar, V. (2012). Frictional properties of cotton-Tencel yarns spun in different spinning systems. Textile Research Journal, 82(8), 755-765.

[10] Kilic, M., \& Okur, A. (2011). The properties of cotton-Tencel and cotton-Promodal blended yarns spun in different spinning systems. Textile Research Journal, 81(2), 156-172.

[11] Kim, H. A. (2017). Physical properties of ring, compact, and air vortex yarns made of PTT/wool/modal and wearing comfort of their knitted fabrics for high emotional garments. The Journal of The Textile Institute, 108(9), 1647-1656.

[12] Li, Q., Brady, P. R., Hurren, C. J., \& Wang, X. G. (2008). The dimensional and mechanical properties of wool/ polyester fabrics made from vortex and ring-spun yarns. Journal of the Textile Institute, 99(6), 561-568.

[13] Liu, X., Jiao, S., \& Wang, F. M. (2013). Configuring the spinning technology of PTT/PET bicomponent filaments according to fabric elasticity. Textile Research Journal, 83(5), 487-498.

[14] Luo, J., Wang, F. M., Li, D., \& Xu, B. (2011). Elasticity of woven fabrics made of polytrimethylene terephthalate/ polyethylene terephthalate bicomponent filaments. Textile Research Journal, 81(8), 865-870.

[15] Luo, J., Wang, F., \& Xu, B. (2011). Factors affecting crimp configuration of PTT/PET bi-component filaments. Textile Research Journal, 81(5), 538-544.

[16] Mhetre, S., \& Parachuru, R. (2010). The effect of fabric structure and yarn-to-yarn liquid migration on liquid transport in fabrics. The Journal of The Textile Institute, 101(7), 621-626. 
[17] Ortlek, H. G., \& Ulku, S. (2005). Effect of some variables on properties of $100 \%$ cotton vortex spun yarn. Textile research journal, 75(6), 458-461.

[18] Ovejero, R. G., Sánchez, J. R., Ovejero, J. B., Valldeperas, J., \& Lis, M. J. (2007). Kinetic and diffusional approach to the dyeing behavior of the polyester PTT. Textile Research Journal, 77(10), 804-809.

[19] Öztürk, M. K., Nergis, B., \& Candan, C. (2011). A study of wicking properties of cotton-acrylic yarns and knitted fabrics. Textile Research Journal, 81(3), 324-328.

[20] Paek, S. L. (1995). Effect of yarn type and twist factor on air permeability, absorbency, and hand properties of open-end and ring-spun yarn fabrics. Journal of the Textile Institute, 86(4), 581-589.
[21] Soe, A. K., Takahashi, M., Nakajima, M., Matsuo, T., \& Matsumoto, T. (2004). Structure and properties of MVS yarns in comparison with ring yarns and open-end rotor spun yarns. Textile research journal, 74(9), 819-826.

[22] Suzuki, Y., \& Sukigara, S. (2013). Mechanical and tactile properties of plain knitted fabrics produced from rayon Vortex yarns. Textile Research Journal, 83(7), 740-751.

[23] Ünal, P. G. (2010). Investigation of some handle properties of fabrics woven with two folded yarns of different spinning systems. Textile Research Journal, 80(19), 2007-2015.

[24] Zhao, L., Hu, H., \& Wang, S. H. (2011). Fuzzy-integrative judgment on the end-use performance of knitted fabrics made with polytrimethylene terephthalate blended yarns. Textile research journal, 81(17), 1739-1747. 